\title{
Excessive Cooling
}

National Cancer Institute

\section{Source}

National Cancer Institute. Excessive Cooling. NCI Thesaurus. Code C63202.

Problem associated with the device producing temperatures that are lower than specified. 